\title{
In vitro conversion and seeded fibrillization of posttranslationally modified prion protein
}

\author{
Jan Stöhr ${ }^{1, a, b}$, Kerstin Elfrink ${ }^{1, b}$, Nicole Weinmann"1, \\ Holger Wille², Dieter Willbold ${ }^{1,3}$, Eva Birkmann ${ }^{1,3}$ \\ and Detlev Riesner ${ }^{1, *}$ \\ ${ }^{1}$ Institut für Physikalische Biologie, Heinrich-Heine- \\ Universität Düsseldorf, D-40225 Düsseldorf, Germany \\ ${ }^{2}$ Institute for Neurodegenerative Diseases and Department \\ of Neurology, University of California, San Francisco, CA \\ 94143, USA \\ ${ }^{3}$ Institute of Structural Biology and Biophysics (ISB-3), \\ Research Center Jülich, D-52425 Jülich, Germany \\ * Corresponding author \\ e-mail: riesner@biophys.uni-duesseldorf.de
}

\begin{abstract}
The conversion of the cellular isoform of the prion protein $\left(\mathrm{PrP}^{\mathrm{C}}\right)$ into the pathologic isoform $\left(\mathrm{PrP}^{\mathrm{Sc}}\right)$ is the key event in prion diseases. To study the conversion process, an in vitro system based on varying the concentration of low amounts of sodium dodecyl sulfate (SDS) has been employed. In the present study, the conversion of full-length $\mathrm{PrP}^{\mathrm{C}}$ isolated from Chinese hamster ovary cells $\left(\mathrm{CHO}-\mathrm{PrP}^{\mathrm{C}}\right)$ was examined. $\mathrm{CHO}-\mathrm{PrP}^{\mathrm{C}}$ harbors native, posttranslational modifications, including the GPI anchor and two N-linked glycosylation sites. The properties of $\mathrm{CHO}-\mathrm{PrP}^{\mathrm{C}}$ were compared with those of full-length and N-terminally truncated recombinant PrP. As shown earlier with recombinant PrP (recPrP90-231), transition from a soluble $\alpha$-helical state as known for native $\operatorname{PrP}^{\mathrm{C}}$ into an aggregated, $\beta$-sheet-rich $\mathrm{PrP}^{\mathrm{Sc}}$-like state could be induced by dilution of SDS. The aggregated state is partially proteinase $\mathrm{K}$ (PK)-resistant, exhibiting a cleavage site similar to that found with $\operatorname{PrP}^{\mathrm{Sc}}$. Compared to recPrP (90-231), fibril formation with $\mathrm{CHO}-$ $\mathrm{PrP}^{\mathrm{C}}$ requires lower SDS concentrations $(0.0075 \%)$, and can be drastically accelerated by seeding with $\operatorname{PrP}^{\mathrm{Sc}}$ purified from brain homogenates of terminally sick hamsters. Our results show that recPrP 90-231 and CHO-PrPC behave qualitatively similar but quantitatively different. The in vivo situation can be simulated closer with $\mathrm{CHO}-\mathrm{PrP}^{\mathrm{C}}$ because the specific PK cleave site could be shown and the seed-assisted fibrillization was much more efficient.
\end{abstract}

Keywords: aggregation; conversion; fibrillization; glycosylation; GPI anchor; prion protein; seeding.

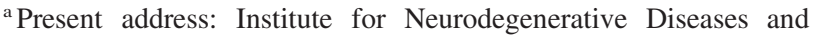
Department of Neurology, University of California, San Francisco, CA 94143, USA.

b These authors contributed equally to this work.
}

\section{Introduction}

Prion diseases are fatal neurodegenerative diseases that include human Creutzfeldt-Jakob disease (CJD), bovine spongiform encephalopathy (BSE) and scrapie in sheep. The key molecular event in prion diseases is the conformational change of the host-encoded prion protein, denoted $\mathrm{PrP}^{\mathrm{C}}$, into the disease-causing isoform $\mathrm{PrP}^{\mathrm{Sc}}$. This transition can occur in vivo either spontaneously, originate from mutations in the PrP sequence, or transmitted by infection with exogenous prions. Regardless of the origin, the conformational change of $\operatorname{PrP}^{\mathrm{C}}$ into $\operatorname{PrP}^{\mathrm{Sc}}$ results in fundamental changes of its biophysical properties. $\mathrm{PrP}^{\mathrm{C}}$ is membrane-bound, rich in $\alpha$-helical secondary structure, soluble in mild detergents and non infectious. In contrast, $\operatorname{PrP}^{\mathrm{Sc}}$ is $\beta$-sheet-rich, insoluble and infectious (for review see Prusiner, 2007). Additionally, proteinase $\mathrm{K}(\mathrm{PK})$ digests $\mathrm{PrP}^{\mathrm{C}}$ completely but truncates $\mathrm{PrP}^{\mathrm{Sc}}$ at the $\mathrm{N}$-terminus up to residue 89 or 90 , resulting in a C-terminal fragment, termed PrP 27-30 that retains its infectious properties (McKinley et al., 1983; Neary et al., 1991; Pan et al., 1993; Safar et al., 1993). If PK digestion is carried out in the presence of detergents, PrP 27-30 assembles into rods, which have the structural and tinctorial properties of amyloid (Prusiner et al., 1983).

The assumption that an amyloidic structure of PrP is favored to confer infectivity led to in vitro-generated synthetic prions. Purified recombinant prion protein [recMoPrP (89230)] was assembled into amyloid fibrils and inoculated into transgenic $(\mathrm{Tg})$ mice expressing the corresponding, N-terminal truncated or natural full-length $\operatorname{PrP}$ sequence; the brains of these mice harbored infectious prions (Legname et al., 2004; Colby et al., 2009). Infectivity titers of synthetic prions in these $\mathrm{Tg}$ mice were low, which could be due to several reasons. First, the structure of the amyloids may not be optimal for infection. Second, the amyloid may have contained only a small subpopulation of infectious fibrils. Third, the recPrP amyloid used to generate the synthetic prions lacked features found in natural prions, such as posttranslational modifications and the polyglucose scaffold, which may have restricted infectivity (Appel et al., 1999; Dumpitak et al., 2005).

Although amyloid structure is a non-obligatory feature of prion diseases, amyloid formation recapitulates several important features of prion diseases, including spontaneous development, a seeding capacity that mimics infection and fidelity of strain replication (Baskakov et al., 2002; Baskakov, 2004; Atarashi et al., 2007; Stöhr et al., 2008). Various in vitro systems have been employed to study amyloid formation and generate prion infectivity. In a sonication-driven cyclic amplification procedure, $\operatorname{PrP}^{\mathrm{Sc}}$ was amplified in extractions from infected and uninfected brain tissue (Sabo- 
rio et al., 2001; Castilla et al., 2005). A very similar technique led to the spontaneous generation of infectivity with partially purified eukaryotic $\operatorname{PrP}^{C}$ (Deleault et al., 2007). In the in-vitro conversion system used in an earlier (Leffers et al., 2005; Stöhr et al., 2008) as well as the present study, the formation of insoluble $\beta$-sheet-rich aggregates or amyloid fibrils was induced by a combination of $\mathrm{NaCl}$ and low concentrations $(\leq 0.03 \%)$ of sodium dodecyl sulfate (SDS). We report that $\mathrm{PrP}^{\mathrm{C}}$ purified from $\mathrm{CHO}$ cells $\left(\mathrm{CHO}-\mathrm{PrP}^{\mathrm{C}}\right)$ can be converted into insoluble aggregates below SDS-concentrations of $0.01 \%$ SDS. These aggregates are partially PKresistant, exhibiting the cleavage site about amino acid 90. This conversion system could be extended to fibril formation of $\mathrm{CHO}-\mathrm{PrP}^{\mathrm{C}}$ by the addition of $\mathrm{NaCl}$ at a specific SDS concentration. Furthermore, fibril formation seeded by $\mathrm{PrP}^{\mathrm{Sc}}$ increased three-fold and occurred five-fold faster with $\mathrm{CHO}-$ $\mathrm{PrP}^{\mathrm{C}}$ as the substrate compared to similar formation reactions using recPrP (Leffers et al., 2005; Stöhr et al., 2008).

\section{Results}

\section{SDS induced aggregation and protease-resistance of CHO-PrP}

The influence of low SDS concentrations (between $0.03 \%$ and $0.01 \%$ ) on the structural transition of recPrP has been described in detail elsewhere (Jansen et al., 2001; Atarashi et al., 2007; Stöhr et al., 2008). Here we tested the influence of $0.05-0.002 \%$ SDS on the solubility and secondary structure of $\mathrm{CHO}-\mathrm{PrP}^{\mathrm{C}}$; solubility was analyzed by differential centrifugation (Figure 1B) and secondary structure by $\mathrm{CD}$ spectroscopy (Figure 1C). After incubation with $0.05 \%$ SDS (and $10 \mathrm{~mm}$ NaPi buffer, pH 7.4), CHO-PrPC was completely soluble (Figure 1B) and appeared to be mostly in an $\alpha$-helical state with slight influence of denaturation (Figure 1C). Decreasing the SDS concentrations to $0.03 \%, 0.01 \%$ and $0.005 \%$ resulted in a distribution of soluble and insoluble $\mathrm{CHO}-\mathrm{PrP}^{\mathrm{C}}$ with increasing portion of insoluble, respectively (Figure 1B). Still lower SDS concentrations (0.002\%) led to complete precipitation of the protein (Figure 1B). The signal of the CD-spectrum of CHO-PrP was lowered in lower SDS concentration. Because of the precipitation the CD-spectrum at $0.002 \%$ (Figure 1C) could not be clearly interpreted whereas the spectrum in $0.01 \%$ showed mostly the features of a $\beta$-sheet rich structure. Under storage conditions $\mathrm{CHO}-$ PrP was kept without any detergent soluble in $1 \mathrm{~mm}$ sodium acetate, $\mathrm{pH} 4$ (Figure 1B) and appeared to be mostly in an $\alpha$-helical state (data not shown).

To determine if the induction of insoluble CHO-PrP aggregates resulting from incubation with $0.002 \%$ SDS was accompanied by the formation of protease-resistance, we digested the samples with PK (1:4 molar ratio, PK:protein) for 3 or $15 \mathrm{~min}$, followed by SDS-PAGE and Western immunoblotting with the $\mathrm{R} 1$ antibody. $\mathrm{R} 1$ recognizes an epitope at the very C-terminal end of PrP (residues 225-231). Therefore, low-molecular-weight fragments of $\mathrm{CHO}-\mathrm{PrP}$ recognized by R1 lack N-terminal regions. Soluble CHO-PrP (incubated with $0.05 \%$ SDS) was also analyzed as a control.
Insoluble $\mathrm{CHO}-\mathrm{PrP}^{\mathrm{C}}$ was partially protease-resistant, with a fragment of $28-32 \mathrm{kDa}$ (Figure 1D). Soluble $\mathrm{CHO}-\mathrm{PrP}^{\mathrm{C}}$ showed a protease-resistant fragment migrating to 18-21 $\mathrm{kDa}$, which disappeared after PK digestion for $15 \mathrm{~min}$. Deglycosylated, protease-resistant fragments of insoluble CHO-PrP showed a prominent band at $\sim 15 \mathrm{kDa}$ (Figure 1D); this fragment size is in good accordance with the molecular weight of $16 \mathrm{kDa}$ for $\operatorname{PrP}$ (90-231), which also correlates to the amino acid sequence of PrP 27-30. The 1-kDa difference in molecular mass is most likely due to the presence of the GPI anchor in CHO-PrPC ${ }^{\mathrm{C}}$, which is known to increase SDS-PAGE mobility by $\sim 1 \mathrm{kDa}$ (Narwa and Harris, 1999). Taken together, these observations indicate that aggregated CHO-PrP is partially protease-resistant and is truncated at a similar site (residue 89/90) as PrP 27-30.

\section{Fibrils formed from CHO-PrPC}

In earlier studies, $\mathrm{SDS}$ and $\mathrm{NaCl}$ were used to form fibrils as well as from recPrP, from denatured and from gel-eluted PrP 27-30, and full-length $\operatorname{PrP}^{\mathrm{C}}$ purified from brain homogenates of non-infected hamsters (Leffers et al. 2005; Stoehr et al. 2008). Those studies had shown that we can induce fibril formation by the addition of $250 \mathrm{~mm} \mathrm{NaCl}$ to the SDS based conversion system. In the absence of $\mathrm{NaCl}$ however, recombinant $\mathrm{PrP}$ was in a partially soluble state $(50 \%$ soluble and $50 \%$ insoluble after a spin at $100000 \mathrm{~g}$ for $1 \mathrm{~h}$ and did not form fibrils. That state of recombinant PrP would compare to $\mathrm{CHO}-\mathrm{PrP}^{\mathrm{C}}$ at $0.01 \%$ SDS (Figure 1B). Therefore, we determined whether fibrils could be formed from $\mathrm{CHO}-\mathrm{PrP}^{\mathrm{C}}$ by addition of $\mathrm{NaCl}$. A sample of $30 \mathrm{ng} / \mu \mathrm{l} \mathrm{CHO}-\mathrm{PrP}^{\mathrm{C}}$ in $0.0075 \%$ and $0.01 \%$ SDS, $250 \mathrm{~mm} \mathrm{NaCl}$ in $10 \mathrm{~mm}$ HEPES buffer, $\mathrm{pH} \mathrm{7.2,} \mathrm{was} \mathrm{incubated} \mathrm{for} 49$ days at $37^{\circ} \mathrm{C}$ under continuous agitation. In case of the use of $0.01 \%$ SDS we observed that $\mathrm{CHO}-\mathrm{PrP}^{\mathrm{C}}$ was not fully insoluble after the long incubation time (Figure 2A) and did not show fibrillar structures as judged from electron microscopy studies (data not shown). Therefore we concentrated on the experimental condition using $0.0075 \%$ SDS. Under these conditions the CHO-PrP was completely insoluble after seven weeks of incubation at $37^{\circ} \mathrm{C}$ (Figure 2A) and formed insoluble fibrils with at least two different ultrastructures, as analyzed by electron microscopy (Figure 2B-D). The majority of these structures appeared as fuzzy and relatively short fibrils, but straighter and longer structures also could be observed (Figure $2 \mathrm{C}$ and $\mathrm{D}$, arrows). The long and more rigid fibrils appeared in a higher order assembly, i.e., smaller fibrils built up those longer structures by lateral association.

To elucidate whether the fibrils were composed of $\operatorname{PrP}^{\mathrm{C}}$, we performed immunogold labeling with two different antibodies: EST123 that recognizes an N-terminal epitope between residues 30-37 (Leclerc et al., 2006) and R2 that recognizes a C-terminal epitope spanning residues 225-231. Both antibodies labeled the fibrils (Figure 3), with R2 showing more efficient labeling than EST123. Thus, full-length CHO-PrP ${ }^{\mathrm{C}}$ appeared to be incorporated into these fibrils. Subsequent bioassays with the in vitro formed fibrils did not reveal any infectious confomers in these samples (data not shown). 
A $\quad \operatorname{PrP}^{\mathrm{C}}$

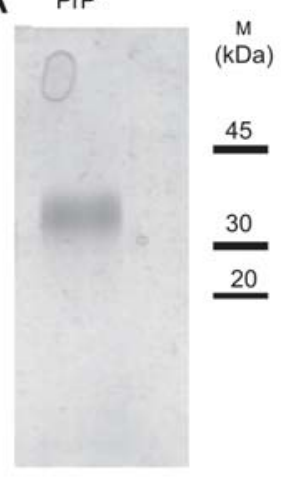

B

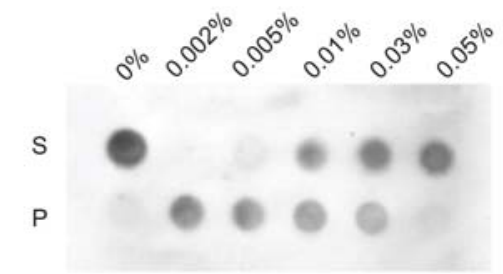

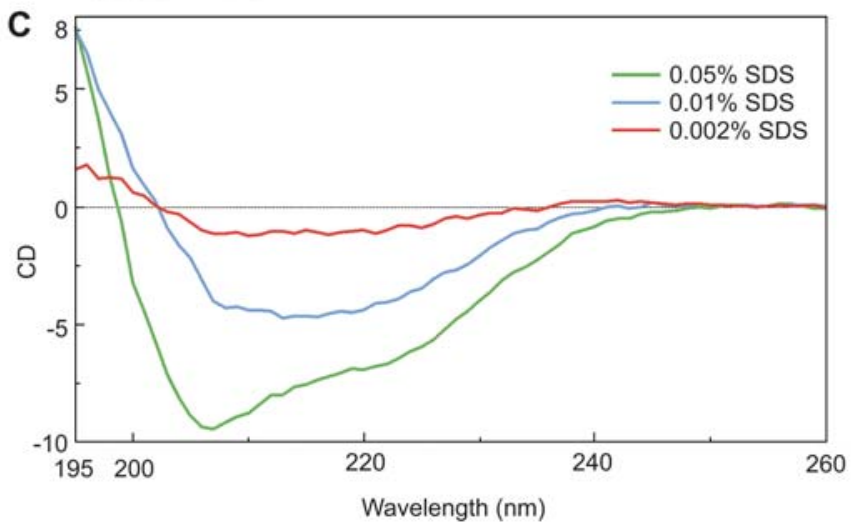

D

\begin{tabular}{r|c|c|c|c|c|c|c|c|c|c|c|c|c|c|}
\hline $\mathrm{t}(\mathrm{PK})$ & $0^{\prime}$ & $3^{\prime}$ & $15^{\prime}$ & $3^{\prime}$ & $15^{\prime}$ & - & $\operatorname{recPrP}$ & $0^{\prime}$ & $3^{\prime}$ & $15^{\prime}$ & $3^{\prime}$ & $15^{\prime}$ & - & recPrP \\
\hline PNGase F & - & - & - & - & - & - & - & + & + & + & + & + & - & + \\
\hline
\end{tabular}

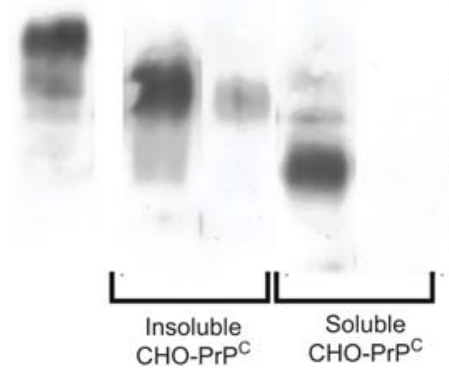

$\underline{30}$

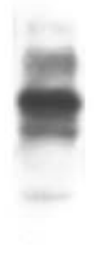

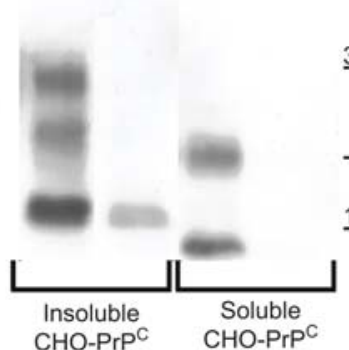

$\underline{30}$

$\underline{14}$

Figure 1 Insoluble, aggregated, and partially protease-resistant PrP formed in the presence of SDS.

(A) $\mathrm{CHO}-\mathrm{PrP}^{\mathrm{C}}$ was purified as described in Elfrink et al. (2008). The purified fraction was analyzed by SDS-PAGE and silver staining. (B) Samples were adjusted to different SDS concentrations, as indicated in phosphate buffer $\mathrm{pH} 7.2$, and incubated for $20 \mathrm{~h}$ at $25^{\circ} \mathrm{C}$. In contrast for the sample indicated with $0 \%$ acate buffer $\mathrm{pH} 4$ was used. Soluble (S) and insoluble (P) samples were separated by centrifugation at $100000 \mathrm{~g}$ for $1 \mathrm{~h}$ at $25^{\circ} \mathrm{C}$, then dot blotted with $3 \mathrm{~F} 4$ antibody. (C) CD spectra recorded prior to solubility analysis. (D) Western immunoblotting before and after deglycosylation using PNGase F show that partially protease-resistant PrP was formed. Insoluble CHO$\mathrm{PrP}^{\mathrm{C}}$ was induced by $0.002 \% \mathrm{SDS}$ and soluble $\mathrm{CHO}-\mathrm{PrP}^{\mathrm{C}}$ with $0.05 \%$ SDS, incubated at $37^{\circ} \mathrm{C}$ for $20 \mathrm{~h}$. PK digestion was performed in a molar ratio of $1: 4(\mathrm{PK}: \mathrm{PrP})$ at $25^{\circ} \mathrm{C}$ for 3 or $15 \mathrm{~min}$, as indicated. For comparison, recPrP (90-231) is shown. Blots were probed with R1 antibody. Apparent molecular masses based on the migration of protein standards are shown in kilodaltons.

\section{Seeded fibril formation of $\mathrm{CHO}-\mathrm{PrP}^{\mathrm{C}}$}

As shown earlier by our and other groups (Atarashi et al., 2007; Colby et al., 2007; Stöhr et al., 2008), naturally occurring $\mathrm{PrP}^{\mathrm{Sc}}$ can seed the formation of fibrils from recPrP. We added naturally occurring, full-length $\operatorname{PrP}^{\mathrm{Sc}}$ purified from brain tissue as described earlier as seeds to fibril formation reactions using $\mathrm{CHO}-\mathrm{PrP}^{\mathrm{C}}$ as substrate. The kinetics of fibril formation were monitored by the ThT fluorescence assay (Figure 4). Upon seeding, the lag phase before the sigmoidal increase of fibrils formation was 5-6 times shorter if CHO$\mathrm{PrP}^{\mathrm{C}}$ was used as substrate as compared to recPrP substrate. 

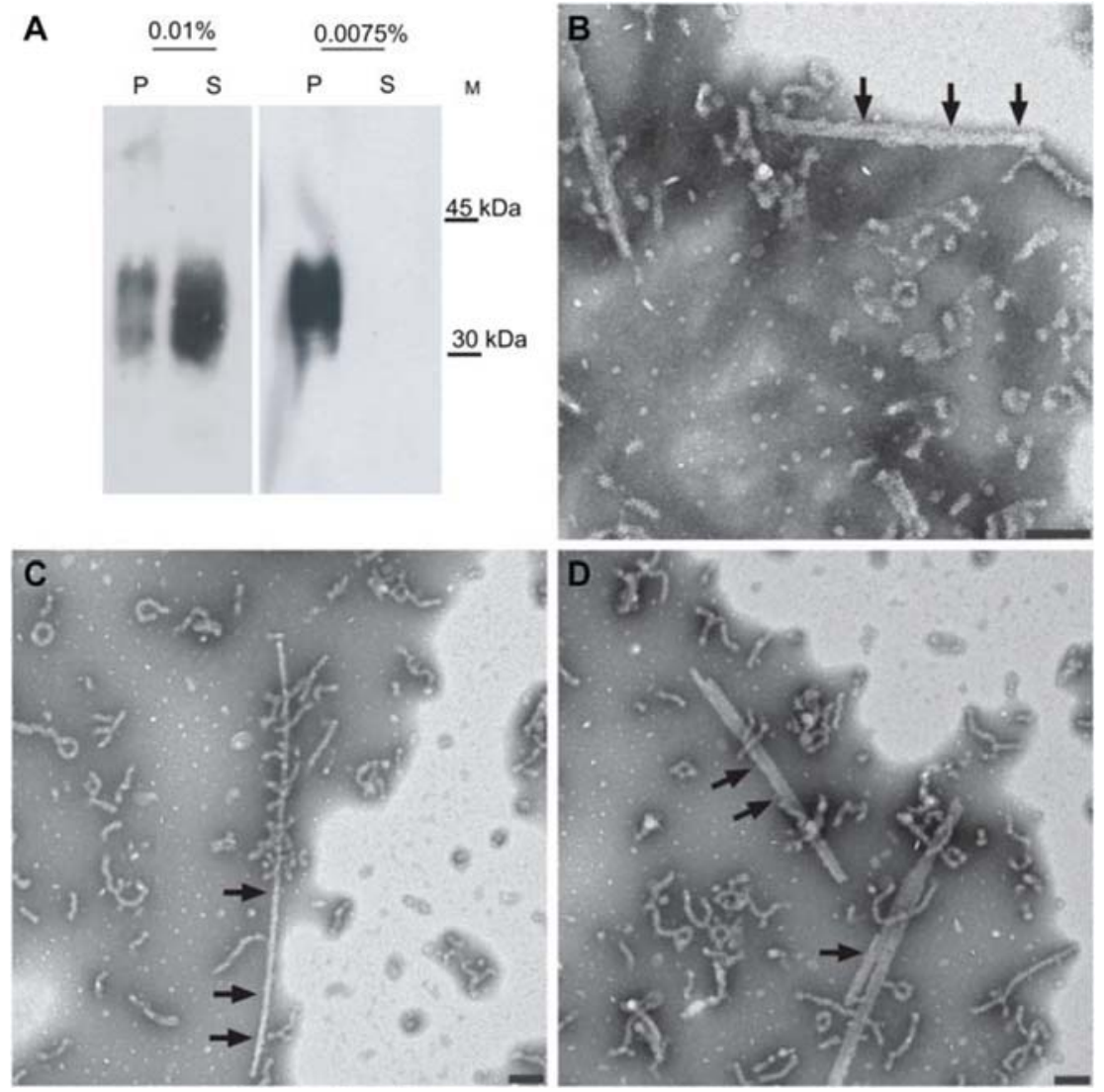

Figure 2 Solubility and Electron microscopy analysis of CHO-PrPC under fibrillization conditions.

(A) Solubility of CHO-PrP ${ }^{C}$. CHO-PrP ${ }^{C}$ was incubated in $10 \mathrm{~mm}$ HEPES (pH 7.2), $250 \mathrm{~mm} \mathrm{NaCl,} 0.0075 \%$ and $0.01 \%$ SDS for seven weeks. The samples were centrifuged at $100000 \mathrm{~g}$ for $1 \mathrm{~h}$. Supernatant (S) and pellet (P) were separated and analyzed by SDS-PAGE and Western blotting. (B-D) Electron micrographs of fibrillar CHO-PrP ${ }^{\mathrm{C}}$. Samples of CHO-PrP after 49 days of incubation at $37^{\circ} \mathrm{C}$ with constant agitation $(650 \mathrm{rpm})$ in the presence of $0.0075 \%$ SDS and $250 \mathrm{~mm} \mathrm{NaCl}$. The majority of the observed structures appeared as fuzzy fibrils, while some fibrils appeared to be more long and rigid (arrows). Bars in B-D represent $100 \mathrm{~nm}$.

Furthermore, the fluorescence intensity was $\sim 3 \times$ higher with CHO-PrP ${ }^{\mathrm{C}}$ compared with equimolar amounts of N-terminally truncated recPrP (Figure 4; Stöhr et al., 2008); the comparison with full length recPrP is described in a recent publication of our group (Panza et al., 2010) showing very similar seeded fibrillization kinetics of N-terminally truncated and full-length recPrP, respectively. These results show that the fully posttranslationally modified $\operatorname{PrP}^{\mathrm{C}}$ is a much more effective substrate for $\mathrm{PrP}^{\mathrm{Sc}}$-seeded fibrillization under the applied conditions.

\section{Discussion}

In the present study, we analyzed the in vitro conformational transition of $\mathrm{PrP}^{\mathrm{C}}$ isolated from $\mathrm{CHO}$ cells, which is posttranslationally modified with $\mathrm{N}$-linked oligosaccharides and a GPI anchor attached at the C-terminus. The structural conversion induced by low concentrations of SDS from a soluble, $\alpha$-helix-dominant structure into insoluble, $\beta$-sheet-rich fibrils could be achieved with $\mathrm{CHO}-\mathrm{PrP}^{\mathrm{C}}$. Aggregates of $\mathrm{CHO}-\mathrm{PrP}^{\mathrm{C}}$, which were formed under low salt conditions, showed partial PK resistance similar to PrP 27-30 (Figure
1). Western immunoblotting of the deglycosylated, proteaseresistant $\mathrm{CHO}-\mathrm{PrP}$ fragment showed a molecular mass that suggests it was cleaved at residue 89/90, as in PrP 27-30.

The fibrils, which are formed after several weeks incorporated intact, CHO-PrP, as demonstrated by immunogold labeling using two antibodies directed against different regions of the protein (Figure 3). We found short and coarse amyloid fibrils, which have been observed also for yeast prions (Schlumpberger et al., 2000; Baxa et al., 2002) and $\beta$-microglobulin ( $\mathrm{Kad}$ et al., 2001). Compared to conditions used previously to form fibrils from full-length $\operatorname{PrP}^{\mathrm{C}}$ purified from hamster brains (0.01\% SDS) (Leffers et al., 2005), slightly lower concentrations of SDS (0.0075\%) were required to form fibrils from $\mathrm{CHO}-\mathrm{PrP}^{\mathrm{C}}$. In comparison $0.03 \%$ SDS were required to form fibrils from truncated recPrP (90-231) (Stoehr et al., 2008) as well as full-length recPrP (23-231) (Panza et al., 2010), respectively. These differences correlate to variations in glycosylation: recPrP lacks glycosylations and its prefibrillar state is stabilized at highest SDS-conditions $(0.03 \%)$. In presence of the glyosyl groups of $\mathrm{PrP}^{\mathrm{C}}$ from hamster brain a lower concentration of SDS $(0.01 \%)$ is needed and the even lager glycosilations of CHOPrP needs the lowest SDS-concentration (0.0075\%) to sta- 

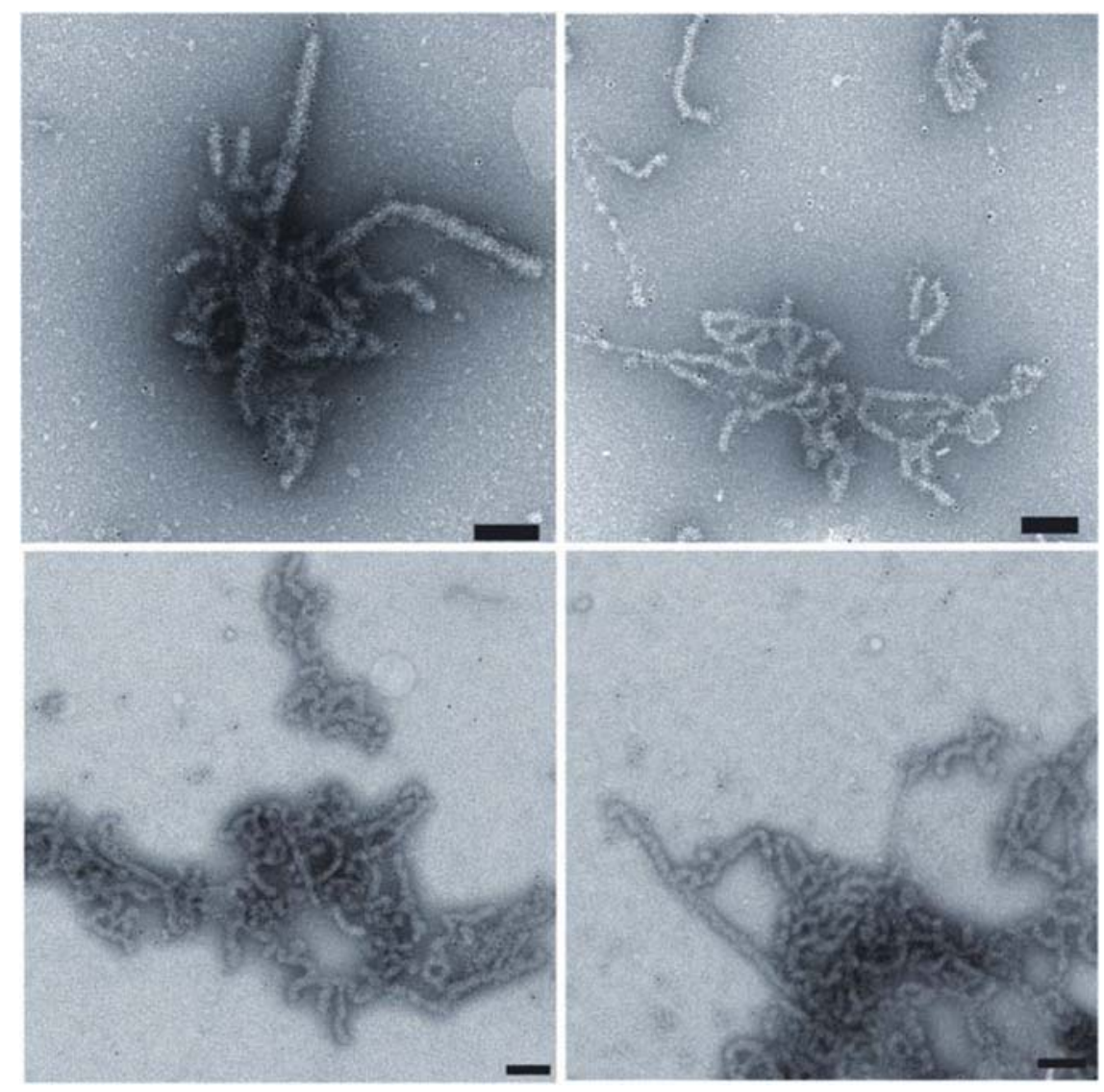

Figure 3 Electron micrographs of immunogold-labeled fibrillar CHO-PrP labeled with HuM-Fab R2 (top row) and with HuM-Fab Est123 (bottom row).

Gold particles appear as black dots on the fibrillar structures. Bars represent $100 \mathrm{~nm}$.

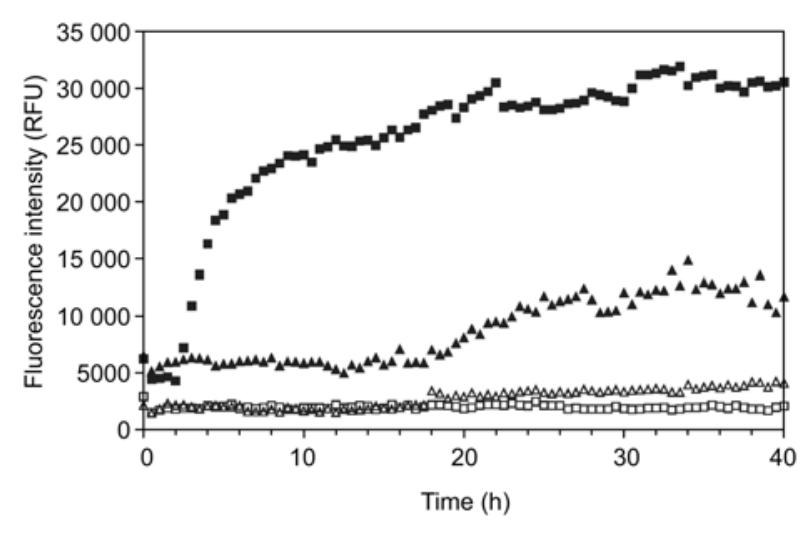

Figure 4 Seeded fibril formation of CHO-PrP ${ }^{\mathrm{C}}$ analyzed by ThT assay.

Seeded fibril formation of CHO-PrP ${ }^{\mathrm{C}}$ (squares, in $0.0075 \%$ SDS, $10 \mathrm{~mm} \mathrm{NaPi}, 250 \mathrm{~mm} \mathrm{NaCl}$ ) compared to recPrP (triangles, $0.025 \%$ SDS, $10 \mathrm{~mm} \mathrm{NaPi}, 250 \mathrm{~mm} \mathrm{NaCl}$ ). Protein concentrations were $860 \mathrm{~nm}$ upon addition of a PTA-precipitated $\mathrm{PrP}^{\mathrm{Sc}}$ seed $\left(1.6 \times 10^{-4}\right.$ brain equivalents $/ \mu \mathrm{l}$ (be/ $\mu \mathrm{l})$, filled symbols). For unseeded reactions (open symbols), equal amounts of PTA-precipitation of noninfected brain homogenate was added. ThT fluorescence was monitored over $40 \mathrm{~h}$ at $37^{\circ} \mathrm{C}$ under constant agitation. bilize the pre-fibrillar state. However, we could not take into account the influence of the GPI-anchor; definitely it might have a minor but not a major quantitative influence. Electron micrographs also confirmed morphological differences between the fibrils formed from recPrP and $\mathrm{CHO}-\mathrm{PrP}^{\mathrm{C}}$. The properties found with $\mathrm{PrP}^{\mathrm{C}}$ from $\mathrm{CHO}$-cells partly resemble those of recombinant PrP but more closely CHO-PrP resembles the in vivo situation. The specific cleavage site around residue 90 is typical for natural prions, and it is detected in polymorphic aggregates of $\operatorname{PrP}^{\mathrm{C}}$. Consequently it is more an intrinsic feature of PrP than a unique marker for infectious particles.

Our seeding experiments showed also closer simulation of the in vivo prion amplification. $\mathrm{CHO}-\mathrm{PrP}^{\mathrm{C}}$ as substrate for $\mathrm{PrP}^{\mathrm{Sc}}$-seeded fibrillization leads to faster more effective fibrillization as compared to recombinant PrP. We interpreted the result, that the recognition between seed and substrate is better because both represent the natural partners. Similar seeding reactions and the generation of infectious prions were also achieved by the protein misfolding cyclic amplification assay (PMCA) (Castilla et al., 2005; Deleault et al., 2007) but were carried out in a complete cellular extract and therefore could not present mechanistic insights of the conversion process. Here we present a minimal system which will be capable of mechanistic investigations into the con- 
version process in future studies. Enormous progress was made in the past by the studies with recombinant PrP, here we completed our knowledge of $\operatorname{PrP}^{\mathrm{C}}$ which is a relevant step to work in the future on the even more in vivo-like situation of $\mathrm{PrP}^{\mathrm{C}}$ anchored in the lipid raft membrane.

\section{Materials and methods}

\section{Prion proteins}

Expression and purification of $\mathrm{PrP}^{\mathrm{C}}$ from eukaryotic $\mathrm{CHO}$ cell cultures, denoted $\mathrm{CHO}-\mathrm{PrP}^{\mathrm{C}}$, were carried out as described previously (Blochberger et al., 1997; Elfrink et al., 2007, 2008) and the purity was controlled by gel electrophoresis and silver staining (Figure 1A) $\mathrm{PrP}^{\mathrm{Sc}}$ was partially purified by precipitation with sodium phosphotungstate (PTA) from brain homogenates of terminally ill Syrian hamsters as described previously (Birkmann et al., 2006).

\section{SDS treatment}

$\mathrm{CHO}-\mathrm{PrP}^{\mathrm{C}}$ was incubated with SDS at $25^{\circ} \mathrm{C}$ for $20 \mathrm{~h}$ in a total volume of $100 \mu \mathrm{l}$. Five different SDS concentrations were employed: $0.05 \%, 0.03 \%, 0.01 \%, 0.005 \%$, and $0.002 \%$. For complete induction of insoluble $\mathrm{PrP}, \mathrm{CHO}-\mathrm{PrP}^{\mathrm{C}}$ was incubated with $0.002 \% \mathrm{SDS}$ at $37^{\circ} \mathrm{C}$ for $20 \mathrm{~h}$.

\section{Circular dichroism (CD) spectroscopy}

CD spectra were recorded with a J-715 spectropolarimeter (Jasco, Gross-Umstadt, Germany) in a $0.1 \mathrm{~cm}$ quartz cuvette at room temperature. The scanning speed was $50 \mathrm{~nm} / \mathrm{min}$ with a step resolution of $1 \mathrm{~nm}$. For each sample, 10 spectra were collected between 195 and $260 \mathrm{~nm}$. Buffer spectra were subtracted from the respective protein spectra.

\section{Protease digestion}

To compare the proteolytic stability of different CHO-PrP ${ }^{\mathrm{C}}$ conformers, PK (Boehringer Mannheim $\mathrm{GmbH}$ ) was added in a molar ratio of 1:4 (PK:CHO-PrP ${ }^{\mathrm{C}}$ ) in $50 \mathrm{~mm} \mathrm{TrisHCl} / 100 \mathrm{~mm} \mathrm{NaCl} /$ $2.5 \mathrm{~mm}$ EDTA. Reactions were performed at $25^{\circ} \mathrm{C}$ for 3 or $15 \mathrm{~min}$, then stopped by the addition of $7.5 \mathrm{~mm}$ phenymethylsulfonyl fluoride. Deglycosylation of CHO-PrP ${ }^{\mathrm{C}}$ was performed using $\mathrm{N}$-acetyl$\beta$-glucosaminylasparagine-amidase (PNGaseF), as specified by the manufacturer (Sigma-Aldrich, St. Louis, USA).

\section{Differential ultracentrifugation}

Solubility of $\mathrm{CHO}-\mathrm{PrP}^{\mathrm{C}}$ was determined by centrifugation at $25^{\circ} \mathrm{C}$ for $1 \mathrm{~h}$ at $100000 \mathrm{~g}$ (TLA-45; Beckmann Optima TM TL; Palo Alto, USA). Samples were then separated into supernatant and pellet, then analyzed by dot blot using monoclonal antibody $3 \mathrm{~F} 4$ for PrP detection.

\section{Electron microscopy, negative stain and immunolabeling}

The immunogold labeling of $\operatorname{PrP}$ was adapted from a previously published protocol (Leffers et al., 2005). A droplet of $5 \mu 1$ containing the sample was placed on the grid and left to adsorb for $5 \mathrm{~min}$. After adsorption to the grid surface, the sample was fixed and washed briefly (in $50 \mu \mathrm{l}$ of: 0.1 and $0.01 \mathrm{M}$ ammonium acetate; $2 \%$ uranyl acetate; water; Tris-buffered saline [TBS]). The washing step was followed by a blocking step with $0.3 \%$ BSA in TBS for 90 min. Then the grids were incubated on a droplet $(50 \mu l)$ containing the primary antibody for $2 \mathrm{~h}$ at room temperature. The grids were washed again $(5 \times 1 \mathrm{~min})$ in TBS containing $0.1 \%$ BSA $(50 \mu \mathrm{l})$, then incubated on a droplet containing the secondary rabbit antihuman antibody (Jackson Immunoresearch, West Grove, PA, USA) in $0.1 \%$ BSA in TBS for $1 \mathrm{~h}$ at room temperature. Again, the grids were washed $5 \times 1 \mathrm{~min}$ in $0.1 \%$ BSA in TBS before being placed onto a droplet of tertiary goat anti-rabbit antibody conjugated to 5-nm gold (Ted Pella, Redding, CA, USA) in $0.1 \%$ BSA in TBS at 1:20 concentration for $30 \mathrm{~min}$. The grids were finally washed $(5 \times 0.1 \%$ BSA/TBS for $1 \mathrm{~min}$ and 1 droplet each of TBS and water) and stained with $2 \%$ ammonium molybdate.

Conventional negative staining was carried out by shortening the adsorption time from $5 \mathrm{~min}$ to $\sim 30 \mathrm{~s}(-1 \mathrm{~min})$ and stained with $2 \%$ ammonium molybdate. The samples were viewed in a Philips/FEI Tecnai F20 electron microscope at $80 \mathrm{kV}$.

\section{SDS-PAGE and Western blotting}

SDS-PAGE (15\%) followed by Western blotting was carried out as described previously (Post et al., 2000) using the anti-PrP monoclonal antibody R1 (Williamson et al., 1998).

\section{Thioflavin T (ThT) assay}

The optimum SDS concentration for spontaneous fibril formation of the respective substrate was used: $0.03 \%$ SDS for recPrP as described earlier (Stöhr et al., 2008) and $0.0075 \%$ SDS for CHO$\mathrm{PrP}^{\mathrm{C}}$. Proteins $(860 \mathrm{nM})$ were loaded onto a $96-$ well plate and incubated with or without the addition of a $\mathrm{PrP}^{\mathrm{Sc}}$ seed; in controls for the unseeded reaction a PTA treated brain homogenate from healthy, uninoculated hamsters was added instead of the $\mathrm{PrP}^{\mathrm{Sc}}$ seed. Fluorescence emission spectra of ThT bound to PrP aggregates were measured with $860 \mathrm{nM}$ of protein and $5 \mu \mathrm{M}$ ThT in $200 \mu$ l. The time dependent fluorescence read-out was performed in a Tecan sapphire plate reader (Tecan Group, Maennedorf, Switzerland) as described previously (Stöhr et al., 2008).

\section{Acknowledgments}

This work was supported by grants from the Deutsche Forschungsgemeinschaft (DFG), EUNetwork of Excellence (NeuroPrion) and the Praesidentenfond of the Helmholtzgemeinschaft (HGF, Virtual Institute of Structural Biology). Jan Stöhr is supported by postdoctoral fellowship of the Deutsche Forschungsgemeinschaft (DFG). We thank S.B. Prusiner for critical reading and helpful discussion for this manuscript. The authors thank Ilka Ostermann for her assistance in the purification of $\mathrm{CHO}-\mathrm{PrP}^{\mathrm{C}}$.

\section{References}

Appel, T.R., Dumpitak, C., Matthiesen, U., and Riesner, D. (1999). Prion rods contain an inert polysaccharide scaffold. Biol. Chem. 380, 1295-1306.

Atarashi, R., Moore, R.A., Sim, V.L., Hughson, A.G., Dorward, D.W., Onwubiko, H.A., Priola, S.A., and Caughey, B. (2007). Ultrasensitive detection of scrapie prion protein using seeded conversion of recombinant prion protein. Nat. Methods 4, 645650 . 
Baskakov, I.V. (2004). Autocatalytic conversion of recombinant prion proteins displays a species barrier. J. Biol. Chem. 279, 7671-7677.

Baskakov, I.V., Legname, G., Baldwin, M.A., Prusiner, S.B., and Cohen, F.E. (2002). Pathway complexity of prion protein assembly into amyloid. J. Biol. Chem. 277, 21140-21148.

Baxa, U., Speransky, V., Steven, A.C., and Wickner, R.B. (2002). Mechanism of inactivation on prion conversion of the Saccharomyces cerevisiae Ure2 protein. Proc. Natl. Acad. Sci. USA 99, 5253-5260.

Birkmann, E., Schafer, O., Weinmann, N., Dumpitak, C., Beekes, M., Jackman, R., Thorne, L., and Riesner, D. (2006). Detection of prion particles in samples of BSE and scrapie by fluorescence correlation spectroscopy without proteinase $\mathrm{K}$ digestion. Biol. Chem. 387, 95-102.

Blochberger, T.C., Cooper, C., Peretz, D., Tatzelt, J., Griffith, O.H., Baldwin, M.A., and Prusiner, S.B. (1997). Prion protein expression in Chinese hamster ovary cells using a glutamine synthetase selection and amplification system. Protein Eng. 10, 1465-1473.

Castilla, J., Saa, P., Hetz, C., and Soto, C. (2005). In vitro generation of infectious scrapie prions. Cell 121, 195-206.

Colby, D.W., Giles, K., Legname, G., Wille, H., Baskakov, I.V., DeArmond, S.J., and Prusiner, S.B. (2009). Design and construction of diverse mammalian prion strains. Proc. Natl. Acad. Sci. USA 106, 20417-20422.

Colby, D.W., Zhang, Q., Wang, S., Groth, D., Legname, G., Riesner, D., and Prusiner, S.B. (2007). Prion detection by an amyloid seeding assay. Proc. Natl. Acad. Sci. USA 104, 20914-20919.

Deleault, N.R., Harris, B.T., Rees, J.R., and Supattapone, S. (2007). Formation of native prions from minimal components in vitro. Proc. Natl. Acad. Sci. USA 104, 9741-9746.

Dumpitak, C., Beekes, M., Weinmann, N., Metzger, S., Winklhofer, K.F., Tatzelt, J., and Riesner, D. (2005). The polysaccharide scaffold of PrP 27-30 is a common compound of natural prions and consists of $\alpha$-linked polyglucose. Biol. Chem. 386, 1149-1155.

Elfrink, K., Nagel-Steger, L., and Riesner, D. (2007). Interaction of the cellular prion protein with raft-like lipid membranes. Biol. Chem. 388, 79-89.

Elfrink, K., Ollesch, J., Stöhr, J., Willbold, D., Riesner, D., and Gerwert, K. (2008). Structural changes of membrane-anchored native PrP(C). Proc. Natl. Acad. Sci. USA 105, 10815-10819.

Jansen, K., Schäfer, O., Birkmann, E., Post, K., Serban, H., Prusiner, S.B., and Riesner, D. (2001). Structural intermediates in the putative pathway from the cellular prion protein to the pathogenic form. Biol. Chem. 382, 683-691.

Kad, N.M., Thomson, N.H., Smith, D.P., Smith, D.A., and Radford, S.E. (2001). Beta(2)-microglobulin and its deamidated variant, N17D form amyloid fibrils with a range of morphologies in vitro. J. Mol. Biol. 313, 559-571.

Leclerc, E., Serban, H., Prusiner, S.B., Burton, D.R., and Williamson, R.A. (2006). Copper induces conformational changes in the $\mathrm{N}$-terminal part of cell-surface $\operatorname{PrP}^{\mathrm{C}}$. Arch. Virol. 151, 21032109.

Leffers, K.W., Wille, H., Stohr, J., Junger, E., Prusiner, S.B., and Riesner, D. (2005). Assembly of natural and recombinant prion protein into fibrils. Biol. Chem. 386, 569-580.
Legname, G., Baskakov, I.V., Nguyen, H.-O.B., Riesner, D., Cohen, F.E., DeArmond, S.J., and Prusiner, S.B. (2004). Synthetic mammalian prions. Science 305, 673-676.

McKinley, M.P., Bolton, D.C., and Prusiner, S.B. (1983). A protease-resistant protein is a structural component of the scrapie prion. Cell 35, 57-62.

Narwa, R. and Harris, D.A. (1999). Prion proteins carrying pathogenic mutations are resistant to phospholipase cleavage of their glycolipid anchors. Biochemistry 38, 8770-8777.

Neary, K., Caughey, B., Ernst, D., Race, R.E., and Chesebro, B. (1991). Protease sensitivity and nuclease resistance of the scrapie agent propagated in vitro in neuroblastoma cells. J. Virol. 65, 1031-1034.

Pan, K.-M., Baldwin, M., Nguyen, J., Gasset, M., Serban, A., Groth, D., Mehlhorn, I., Huang, Z., Fletterick, R.J., Cohen, F.E., et al. (1993). Conversion of $\alpha$-helices into $\beta$-sheets features in the formation of the scrapie prion proteins. Proc. Natl. Acad. Sci. USA 90, 10962-10966.

Panza, G., Luers, L., Stöhr, J., Nagel-Steger, L., Weiß, J., et al. (2010). Molecular interactions between prions as seeds and recombinant prion proteins as substrates resemble the biological interspecies barrier in vitro. PLoS ONE 5: e14283. doi:10.1371/ journal.pone.0014283.

Post, K., Brown, D.R., Groschup, M., Kretzschmar, H.A., and Riesner, D. (2000). Neurotoxicity but not infectivity of prion proteins can be induced reversibly in vitro. Arch. Virol. (Suppl.), 16, 265-273.

Prusiner, S.B. (2007). Prions. In: Fields Virology, D.M. Knipe, P.M. Howley, D.E. Griffin et al. eds. (Philadelphia: Lippincott Williams \& Wilkins), pp. 3059-3092.

Prusiner, S.B., McKinley, M.P., Bowman, K.A., Bolton, D.C., Bendheim, P.E., Groth, D.F., and Glenner, G.G. (1983). Scrapie prions aggregate to form amyloid-like birefringent rods. Cell 35, 349358.

Saborio, G.P., Permanne, B., and Soto, C. (2001). Sensitive detection of pathological prion protein by cyclic amplification of protein misfolding. Nature $411,810-813$.

Safar, J., Roller, P.P., Gajdusek, D.C., and Gibbs, C.J.J. (1993). Thermal-stability and conformational transitions of scrapie amyloid (prion) protein correlate with infectivity. Protein Sci. 2, 2206-2216.

Schlumpberger, M., Wille, H., Baldwin, M.A., Butler, D.A., Herskowitz, I., and Prusiner, S.B. (2000). The prion domain of yeast Ure2p induces autocatalytic formation of amyloid fibers by a recombinant fusion protein. Protein Sci. 9, 440-451.

Stöhr, J., Weinmann, N., Wille, H., Kaimann, T., Nagel-Steger, L., Birkmann, E., Panza, G., Prusiner, S.B., Eigen, M., and Riesner, D. (2008). Mechanisms of prion protein assembly into amyloid. Proc. Natl. Acad. Sci. USA 105, 2409-2414.

Williamson, R.A., Peretz, D., Pinilla, C., Ball, H., Bastidas, R.B., Rozenshteyn, R., Houghten, R.A., Prusiner, S.B., and Burton, D.R. (1998). Mapping the prion protein using recombinant antibodies. J. Virol. 72, 9413-9418.

Received August 6, 2010; accepted January 10, 2011 